\title{
An Investigation on People Living with HIV and AIDS Rejected by Medical Staff in China
}

\section{Yong Yu ( $\nabla$ yuyongsheyi@163.com )}

Guangxi Normal University

\section{Zijue Chang}

Guangxi Normal University

\section{Xiuya Liu}

Guangxi Normal University

Yu Lu

Guangxi Normal University

\section{Research article}

Keywords: HIV/AIDS, Medical staff, Reject treatment, Willingness to diagnose and treat

Posted Date: November 23rd, 2020

DOl: https://doi.org/10.21203/rs.3.rs-111778/v1

License: (c) (i) This work is licensed under a Creative Commons Attribution 4.0 International License. Read Full License 


\section{Abstract}

Background: A cross-sectional survey was conducted from the two perspectives of the incidence, type, help-seeking situation of PLWHA囚People living with HIV and AIDS『rejected by medical staff and the willingness of medical staff to diagnose and treat PLWHA to analyze the realistic problem of PLWHA and AIDS rejected by medical staff under the current Chinese cultural background.

Methods: 1500 people were selected from PLWHA users in the WeChat work account of a Center for Disease Control and Prevention(CDC), and 1000 medical staff were selected from a third-class hospital in Guangxi, China. The self-compiled general information questionnaire and PLWHA medical rejection questionnaire were used to conduct a one-to-one WeChat online survey on PLWHA. A questionnaire on HIV/AIDS clinical knowledge, a questionnaire on HIV/AIDS attitude, and a questionnaire on the willingness to diagnose and treat PLWHA with clinical surgery were used to conduct a face-to-face survey on the selected medical staff.

Results: 1146 valid PLWHA samples and 890 medical staff samples were obtained. 30.2\% (346/1146) of HIV-infected/AIDS patients had experienced refusal from medical staff when visiting a hospital for nonHIV/AIDS-related diseases since the diagnosis of HIV+; 17.1\% (196/1146) of HIV-infected/AIDS patients had been rejected by medical staff in the hospital due to other diseases in the past 12 months and $10.8 \%$ (124/1146) had been rejected in clinical surgeries; after receiving a refusal, $58.2 \%$ (114/196) of the HIVinfected/AIDS patients never asked for help, while only $37.8 \%$ (74/196) of the refused patients were resolved accordingly. Only $38.7 \%$ of medical staff clearly expressed their willingness to provide surgical treatment or post-operative nursing services for HIV-infected/AIDS patients. After controlling other factors, the answer accuracy of HIV/AIDS-related knowledge [odds ratio (OR) $=2.41,95 \%$ confidence interval (CI): $1.31,4.43]$ and the attitudes towards HIV/AIDS (OR=6.74, 95\% Cl: $3.59,12.66)$ were the influencing factors for medical staff's willingness to diagnosis and treat HIV-infected /AIDS patients with clinical surgery.

Conclusions: Rejection by the medical staff is a common phenomenon during the treatment of HIVinfected/AIDS patients in China and the willingness of medical staff to diagnose and treat HIVinfected/AIDS patients is relatively weak.

\section{Background}

It has been nearly 40 years since the first case of AIDS was recorded in 1981. The world has suffered greatly due to AIDS and its pathogen; HIV (Human Immunodeficiency Virus). Although much progress has been made in the prevention and treatment of HIV/AIDS over the past decade, the HIV pandemic remains the most serious challenge facing the global public health field ${ }^{[1]}$. According to data from National Center for AIDS/STD Control and Prevention (NCAIDS), China CDC, a total of 849,602 cases of PLWHA were reported nationwide as of September 30, 2018; including 497,231 HIV-infected patients and 352,371 AIDS patients ${ }^{[2]}$. However, the discrimination and stigmatization of PLWHA has inevitably produced a culture of 
discrimination. In China, most people still regard HIV/AIDS as only the consequence of homosexuality, commercial sex, and drug abuse ${ }^{[3][4][5][6]}$. In fact, most HIV infections in China occur in rural areas ${ }^{[7][8]}$.In October 2012, Xiaofeng, an HIV-infected person, was admitted to Tianjin Cancer Hospital for lung cancer but was forced to leave the hospital on the eve of the operation because of HIV. Afterwards, Xiaofeng had to modify the HIV test report privately and obtain an operation in another hospital in Tianjin. Later, Li Hu, the former head of the Tianjin Haihe Star AIDS Working Group, disclosed the incident through Sina Weibo; which caused huge controversy throughout China. On November 21st, 2012, Chinese Premier Li Keqiang immediately called the head of the Ministry of Public Health after seeing relevant news reports; asking the health department to take practical measures to protect the rights of AIDS patients to receive medical treatment without discrimination and to protect the safety of medical staff. The next day, the Ministry of Public Health issued the "Notice on Strengthening Medical Services for HIV-Infected/AIDS Patients". After investigation, the Tianjin Health Bureau stated that Tianjin Cancer Hospital had prevaricated AIDS patients. It revealed the serious discrimination against HIV-infected/AIDS patients seeking medical care in Chinese medical and health service institutions, and also highlighted an important issue: refusal of treatment by medical staff is a common phenomenon during the treatment of HIV-infected/AIDS patients in China due to misunderstandings and discrimination against the PLWHA; many medical workers are less willing to diagnose and treat PLWHA.

Being rejected by medical staff in this study refers to the fact that medical institutions prevaricate or refuse to treat patients with HIV-infected/AIDS ${ }^{[9]}$. Their willingness to diagnose and treat patients refers to the attitude of health service providers to provide emotional, material and technical support to PLWHA ${ }^{[10]}$. Since the 1990s, PLWHA's health status has improved with the use and promotion of Highly Active AntiRetroviral Therapy(HARRT); this includes reduced morbidity and mortality, longer survival time and improved quality of life $\mathrm{e}^{[11][12]}$. Although there is no cure for HIV/AIDS, significant progress has been made in recent years, especially in the development of HARRT; which has effectively extended the lifespan of many PLWHA and reduced opportunistic infections ${ }^{[13][14]}$. Therefore, the accessibility of long-term PLWHA in medical and health services has become the primary concern of PLWHA ${ }^{[15]}$. However, China has a higher PLWHA mortality rate due to the difficulty in accessing comprehensive disease-related prevention, treatment and care services ${ }^{[16]}$ compared with developed countries. There are still many medical ethics disputes over the rejection of PLWHA in many countries. In Germany, $28 \%$ of health service workers are unwilling to provide medical services to PLWHA to protect themselves and their families ${ }^{[17]}$. The research results of $\mathrm{Cai}^{[18]}$ and Oyeyemi ${ }^{[19]}$ also proved that most nurses are reluctant to provide nursing services for PLWHA. This study conducts a cross-sectional survey from the two perspectives of the incidence, type, help-seeking situation of PLWHA(People living with HIV and AIDS)rejected by medical staff and the willingness of medical staff to diagnose and treat PLWHA to analyze the realistic problem of PLWHA and AIDS rejected by medical staff under the current Chinese cultural background.

\section{Methods}

\section{Participants}


The objects of this study consider two aspects: PLWHA and the medical staff.

PLWHA belongs to the inaccessible population. According to the pilot survey, it is difficult to guarantee the privacy of the investigation and the personal privacy of PLWHA during the field investigation at the CDC and the outpatient department of Infectious Disease Hospital. The PLWHA's cooperation degree is quite low and the investigation is difficult to proceed. In consideration of the current development and popularization of WeChat media, this study took the PLWHA users on the WeChat public account established by the XX City CDC as the research object. The WeChat platform was established in July 2014 to provide the PLWHA and people affected by HIV/AIDS with popular scientific knowledge concerning AIDS, psychological counseling, and medication guidance. The platform has about 74000 online fans and accumulated more than 140000 followers; $90 \%$ of whom are HIV-infected, others are family members, volunteers, AIDS specialists in grassroots $C D C$ and designated hospitals, others are AIDS-phobic people and numerous people interested in HIV/AIDS. For PLWHA with further consultation needs on the WeChat platform, we will provide a dedicated WeChat ID for further communication. As of September 1st 2018, there are 9,987 PLWHA in the 3 WeChat accounts of the CDC. Based on the sample size standards for sentinel surveillance of high-risk groups of sexually transmitted infections (usually in 250 400) recommended by the World Health Organization and the $\operatorname{CDC}^{[20]}$ and the convenience of contacting samples of "we media" and the objective conditions limiting the difficulty of investigation on sensitive issues such as HIV/AIDS, the minimum sample size of PLWHA has been determined to be 1,500 people. In this study, simple random sampling was used to select samples. Firstly, we established a sampling frame containing 9,987 PLWHA and then selected one infected person from the top 10 of the list as a random starting point. Next, we sequentially selected the remaining sample units; 1 person was selected every 6 people until 1,500 people were drawn. The researchers contacted participants using the WeChat ID and conducted a one-to-one questionnaire survey via the WeChat line.

The medical staff in this study are doctors and nurses from a third-class hospital in Guangxi. The hospital, directly under the Health Commission of Guangxi Zhuang Autonomous Region, is a class A, grade III general hospital integrating medical treatment, teaching, scientific research, prevention, health care, rehabilitation and other functions. It currently has more than 1,200 hospital beds and 1,900 employees. Approved by the hospital's ethics committee and based on the hospital's staff roster, we randomly selected 400 clinicians and 600 nurses in the hospital. The investigators contacted the selected doctors and nurses to conduct a one-to-one questionnaire survey with them. The failure of the respondent to cooperate with the investigator on three visits was deemed as a refusal of the investigation.

\section{Questionnaires}

The questionnaire consists of two parts: firstly, the general information section which includes social demographic characteristics, namely gender, age, nationality, education, marital status, and average monthly income. PLWHA should be inquired about the route of HIV infection and medical staff should be asked about employment years, title and department, etc. Secondly, the PLWHA medical rejection section which includes the following 5 items: since the diagnosis of HIV+, has there been a refusal from medical staff when visiting a hospital, whether there has been a refusal from medical staff when visiting a 
hospital in the last 12 months. For PLWHA who have been rejected in the past 12 months, we need to further ask about the types of rejection: non-surgical disease outpatient service, clinical surgery, clinical postoperative care, non-postoperative care, psychological outpatient service, other hospital treatments, etc. Fourthly, the patients seeking help after a refusal and finally if the refusal has been properly resolved after the patients sought help. In addition, a self-compiled questionnaire on HIV/AIDS clinical knowledge among medical staff, with 24 items has been issued. To ensure the quality of the survey, we firstly conducted a pre-survey with 40 medical staff before adjusting, improving and modifying the structure and content of the questionnaire based on the results. The final questionnaire has good reliability and validity, as well as the Cronbach has a coefficient $>0.7$. The questionnaire on HIV/AIDS attitude has 24 items; which are derived from the AIDS Attitude Scale (AAS) compiled by Froman ${ }^{[21]}$ and a related questionnaire by Aeree ${ }^{[22]}$ as well as the self-compiled questionnaire of medical staff's willingness to diagnose and treat PLWHA has a total of 11 items. The questionnaire includes emotional, material, and technical support. It has good reliability and validity as well as a Cronbach reading of a coefficient $>0.7$. Quality control

All PLWHA samples were investigated by investigators for WeChat one-to-one online interviews, while medical staff samples were investigated by investigators for one-on-one on-site questionnaires. The investigators were uniformly trained and each online investigation was conducted in a quiet, undisturbed environment. Every questionnaire must be verified on-site and the items that were not answered in time or clearly by the respondent were questioned and confirmed based on ensuring compliance with ethical principles.

\section{Statistical method}

EpiData 3.1 was used to establish a database and SPSS 20.0 was used for statistical analysis. The test level (a) was taken as 0.05 and the positive rate of different groups was compared by the $\chi 2$ test (Pearson Chi-Square Test). The t-test was used to compare the measurement indexes between different groups, and the Ordinal rank regression analysis was used for multivariate analysis.

\section{Results}

A questionnaire survey of 1500 PLWHA was conducted from September 1, 2018 to March 1, 2019. Among them, 101 people could not be contacted because their WeChat ID was no longer used and 220 people refused to cooperate with the survey. 13 people interrupted the online investigation due to private affairs during the investigation. The number of PLWHA who finally completed the survey was 1166 and the response rate was $77.27 \%$. After excluding 20 invalid questionnaires with serious logical confusion, 1146 valid PLWHA samples were ultimately obtained. As shown in Table 1, the oldest age was 66 years old, the youngest was 17 years old, and the mean age was $(31 \pm 8)$ years old. $96.1 \%(1101 / 1146)$ of the respondents were male, $93.6 \%$ (1073/1146) were Han nationality, 53.0\% (608/1146) had a bachelor's, master's degree or above, $72.1 \%$ (826/1146) were unmarried, $58.5 \%$ (670/1146) were from cities, $43.5 \%$ (498/1146) were the only children, and $10.6 \%(121 / 1146)$ were students. 
Table 1

Social Demographic Characteristics of PLWHA [n (\%)]

\begin{tabular}{|c|c|c|}
\hline \multirow[t]{2}{*}{ Variable } & \multicolumn{2}{|l|}{ PLWHA(N = 1146) } \\
\hline & number of people(N) & composition(\%) \\
\hline \multicolumn{3}{|l|}{ Gender } \\
\hline Male & 1101 & 96.1 \\
\hline Female & 45 & 3.9 \\
\hline \multicolumn{3}{|l|}{ Nationality } \\
\hline Han & 1073 & 93.6 \\
\hline Minority & 73 & 6.4 \\
\hline \multicolumn{3}{|l|}{ Education } \\
\hline Master degree and above & 100 & 8.7 \\
\hline Bachelor degree & 508 & 44.3 \\
\hline Junior college & 252 & 22.0 \\
\hline High school or technical secondary school & 189 & 16.5 \\
\hline Junior high school & 89 & 7.8 \\
\hline Primary school & 8 & 0.7 \\
\hline \multicolumn{3}{|l|}{ Marital status } \\
\hline Unmarried & 826 & 72.1 \\
\hline Married & 245 & 21.4 \\
\hline Divorced & 69 & 6.0 \\
\hline Widowed & 6 & 0.5 \\
\hline \multicolumn{3}{|l|}{ Domicile } \\
\hline City & 670 & 58.5 \\
\hline Rural area & 476 & 41.5 \\
\hline \multicolumn{3}{|l|}{ Only child } \\
\hline Yes & 498 & 43.5 \\
\hline No & 648 & 56.5 \\
\hline \multicolumn{3}{|l|}{ Are you a student } \\
\hline Yes & 121 & 10.6 \\
\hline
\end{tabular}




\begin{tabular}{|lll|}
\hline Variable & PLWHA(N = 1146) & \\
\cline { 2 - 3 } & number of people(N) & composition(\%) \\
\hline No & 1025 & 89.4 \\
\hline
\end{tabular}

A questionnaire survey of medical staff was conducted in July 2020. Finally, 890 valid samples were obtained, including 312 doctors and 578 nurses, with a total response rate of $89.0 \%$ (890/1000). Among the 890 medical staff, the oldest is 53 years old, and the youngest is 18 years old. The median age is P50 $=29$ years $(\mathrm{P} 25=25, \mathrm{P} 75=34)$; male 21.1\% (187/890), female 78.9\% $(703 / 890)$; doctors $35.1 \%$ (312/890), nurses 64.9\% (578/890); unmarried 44.3\% (393/890), married 55.7\% (497/890). 46.5\% $(414 / 890)$ have been employed for 1 to 5 years, 53.5\% (476/890) have been employed for more than 5 years; $47.0 \%$ (418/890) were junior professional titles, and $37.5 \%$ (334/890) were intermediate professional titles, and 15.5\% (138/890) were senior professional titles; $1.3 \%$ (12/890) graduated from high school, technical secondary school or below, 27.0\% (240/890) graduated from junior college, 56.9\% $(506 / 890)$ graduated from bachelor's degree and $14.8 \%$ (132/890) graduated with a master's degree or above. In addition, 43.1\% (384/890) indicated exposure to PLWHA in past jobs. 
Table 2

Social Demographic Characteristics of Medical Staff

\begin{tabular}{|c|c|c|c|c|c|c|c|c|}
\hline \multirow[t]{2}{*}{ Variable } & \multicolumn{2}{|c|}{$\begin{array}{l}\text { Total } N= \\
\mathbf{8 9 0}\end{array}$} & \multicolumn{2}{|c|}{$\begin{array}{l}\text { Doctors } \mathrm{N}= \\
312\end{array}$} & \multicolumn{2}{|c|}{$\begin{array}{l}\text { Nurses N= } \\
578\end{array}$} & \multirow[t]{2}{*}{$x^{2}$} & \multirow[t]{2}{*}{$\mathbf{P}$} \\
\hline & $\mathrm{N}$ & $\%$ & $\mathrm{~N}$ & $\%$ & $\mathrm{~N}$ & $\%$ & & \\
\hline Male & 187 & 21.1 & 139 & 44.6 & 48 & 8.3 & \multirow[t]{2}{*}{76.98} & \multirow[t]{2}{*}{0.000} \\
\hline Female & 703 & 78.9 & 175 & 56.0 & 528 & 91.3 & & \\
\hline Age冈29 & 428 & 48.1 & 114 & 36.5 & 314 & 54.3 & \multirow[t]{2}{*}{12.84} & \multirow[t]{2}{*}{0.000} \\
\hline Age $\geq 29$ & 462 & 51.9 & 198 & 63.5 & 264 & 45.7 & & \\
\hline Unmarried & 393 & 44.2 & 104 & 33.3 & 290 & 50.2 & \multirow[t]{2}{*}{11.65} & \multirow[t]{2}{*}{0.000} \\
\hline Married & 497 & 55.8 & 208 & 66.7 & 288 & 49.8 & & \\
\hline Employed for 1 to 5 years & 414 & 46.5 & 114 & 36.5 & 300 & 51.9 & \multirow[t]{2}{*}{9.61} & \multirow[t]{2}{*}{0.002} \\
\hline Employed for more than 5 years & 476 & 53.5 & 198 & 63.5 & 278 & 48.1 & & \\
\hline Junior professional titles & 418 & 47.0 & 134 & 42.9 & 284 & 49.1 & \multirow[t]{2}{*}{1.56} & \multirow[t]{2}{*}{0.212} \\
\hline $\begin{array}{l}\text { Intermediate/senior professional } \\
\text { titles }\end{array}$ & 472 & 53.0 & 178 & 57.1 & 294 & 50.9 & & \\
\hline $\begin{array}{l}\text { Graduated from junior college or } \\
\text { below }\end{array}$ & 252 & 28.3 & 22 & 7.1 & 230 & 39.8 & \multirow[t]{2}{*}{53.51} & \multirow[t]{2}{*}{0.000} \\
\hline $\begin{array}{l}\text { Graduated from bachelor's degree } \\
\text { or above }\end{array}$ & 638 & 71.7 & 290 & 92.9 & 348 & 60.2 & & \\
\hline Exposure to PLWHA in past jobs & 384 & 43.1 & 36 & 11.5 & 348 & 60.2 & 97.83 & 0.000 \\
\hline
\end{tabular}

\section{The incidence, type, help-seeking situation of PLWHA rejected by medical staff}

Table 3 describes the incidence and help-seeking situation of rejection experienced by PLWHA. $30.2 \%$ (346/1146) of PLWHA indicated that they had encountered refusal of treatment in hospital since their diagnosis of HIV+; 17.1\% (196/1146) of PLWHA indicated that they had encountered at least one different type of rejection (Non-surgical disease outpatient rejection, clinical surgery rejection, clinical postoperative care rejection, non-postoperative care rejection, psychological outpatient rejection, and other hospital rejection) in hospital in the last 12 months. Among them, the clinical surgery rejection rate is the highest; up to $10.8 \%$ (124/1146), followed by the refusal of post-operative care, $8.2 \%(94 / 1146)$. $13.4 \%(154 / 1146)$ had been rejected by the doctor and $8.8 \%$ of the participants (101/1146) had been rejected by the nurse. Among 196 people who were rejected in the last 12 months, 114 (9.9\%) said they had never asked for help after being rejected and 63 (5.5\%) said they had asked volunteers for help, 29 $(2.5 \%)$ reported to the local health department and asked for help. Moreover, only 14 people $(1.2 \%)$ had sought help from friends or family members and 74 people $(6.5 \%)$ had received further treatment. The $\chi 2$ 
test results showed that there was no significant difference in the incidence, type and help-seek data of rejection in between men who have sex with men and those infected by other means. 
Table 3

The incidence and type of PLWHA rejected by medical staff [n (\%)]

\begin{tabular}{|c|c|c|c|c|c|}
\hline Variable & $\begin{array}{l}\text { Total }(\mathrm{N}= \\
1146)\end{array}$ & $\begin{array}{l}\text { Men who have } \\
\text { sex with men }(\mathrm{N}= \\
\text { 951) }\end{array}$ & $\begin{array}{l}\text { Infected by } \\
\text { other means }(\mathrm{N} \\
=195)\end{array}$ & $x^{2}$ & $\mathbf{P}$ \\
\hline $\begin{array}{l}\text { Rejected since their diagnosis } \\
\text { of } \mathrm{HIV}+{ }^{a}\end{array}$ & $346(30.2)$ & $281(29.5)$ & $66(33.8)$ & 1.10 & 0.305 \\
\hline $\begin{array}{l}\text { Rejected in the last } 12 \\
\text { months }{ }^{\text {a }}\end{array}$ & 196(17.1) & 167(17.6) & $29(14.9)$ & 0.83 & 0.404 \\
\hline Rejected by doctors & $154(13.4)$ & $123(12.9)$ & $26(15.9)$ & \# & \# \\
\hline Rejected by nurses & $101(8.8)$ & $81(8.2)$ & $20(10.3)$ & \# & \# \\
\hline \multicolumn{6}{|l|}{ Types of rejection } \\
\hline $\begin{array}{l}\text { Non-surgical disease } \\
\text { outpatient rejection }\end{array}$ & $26(2.3)$ & $20(2.0)$ & $6(3.1)$ & \# & \# \\
\hline Clinical surgery rejection & $124(10.8)$ & $97(10.2)$ & $27(13.8)$ & \# & \# \\
\hline $\begin{array}{l}\text { Clinical postoperative care } \\
\text { rejection }\end{array}$ & $94(8.2)$ & $73(7.7)$ & $21(10.8)$ & \# & \# \\
\hline $\begin{array}{l}\text { Non-postoperative care } \\
\text { rejection }\end{array}$ & $32(2.8)$ & $29(3.0)$ & $3(1.5)$ & \# & $\#$ \\
\hline $\begin{array}{l}\text { Psychological outpatient } \\
\text { rejection }\end{array}$ & $5(0.4)$ & $4(0.4)$ & $1(0.5)$ & \# & $\#$ \\
\hline Other hospital rejection & $18(1.6)$ & $14(1.5)$ & $4(2.1)$ & \# & $\#$ \\
\hline \multicolumn{6}{|l|}{$\begin{array}{l}\text { Asked for help after being } \\
\text { rejected }\end{array}$} \\
\hline Never asked for help & 114(9.9) & 101(10.6) & $13(6.6)$ & 2.82 & 0.114 \\
\hline $\begin{array}{l}\text { Asked for help from friends or } \\
\text { family members }\end{array}$ & $14(1.2)$ & $3(0.3)$ & $11(5.6)$ & \# & $\#$ \\
\hline Asked volunteers for help & $63(5.5)$ & $52(5.5)$ & $11(5.6)$ & \# & \# \\
\hline $\begin{array}{l}\text { Reported to the local health } \\
\text { department and asked for } \\
\text { help }\end{array}$ & $29(2.5)$ & $20(2.1)$ & $9(4.6)$ & \# & $\#$ \\
\hline \multicolumn{6}{|l|}{$\begin{array}{l}\text { Received further treatment } \\
\text { after asking for help }\end{array}$} \\
\hline Yes & $74(6.5)$ & $64(6.7)$ & $10(5.1)$ & 0.69 & 0.522 \\
\hline No & 122(10.6) & $110(11.6)$ & $12(6.2)$ & 4.98 & 0.029 \\
\hline
\end{tabular}

a Refers to one or more of the 6 types of rejection: non-surgical disease outpatient rejection, clinical surgery rejection, clinical postoperative care rejection, non-postoperative care rejection, psychological 
outpatient rejection, and other hospital rejection.

\section{The accuracy of medical staff's answer to HIV/AIDS knowledge}

As displayed in Table 4, for the 890 medical staff who responded to about $24 \mathrm{HIV/AIDS}$ knowledge questions, the median number of accurate answers was 15 questions ( $P 25=12, P 75=18$ ). The $\chi 2$ test results show that the two groups of doctors and nurses have statistical differences in their responses to 13 questions $(2,3,5,6,8,9,13,14,15,17,19,21,22)$. Among them, the correct answer rate of 6 questions in the doctor group $(2,3,5,15,19,22)$ was higher than that of the nurse group; while the answer rate of 7 questions in the nurse's group $(6,8,9,13,14,17,21)$ was higher than that of the doctor's group. According to the median number of questions answered accurately P50 $=15$, all the samples were divided into two groups ( $\leq 14=1,>15=2$ ): group 1 was the group with lower accuracy and group 2 with higher accuracy. The $\chi 2$ test results show that there is a statistically significant difference in the HIV/AIDS knowledge between the two groups of doctors and nurses $(X 2=6.13, P=0.01)$. After controlling for age, marital status, education, professional title, employment years and other factors, the difference between the two groups was still statistically significant $(\mathrm{OR}=1.69,95 \% \mathrm{Cl}[1.09,2.61])$ and the nurse group had higher accuracy in answering HIV/AIDS knowledge than the doctor group. 
Table 4

The answer accuracy of HIV/AIDS-related knowledge(\%)

Item

Total Doctors Nurses $\chi^{2}$

$\begin{array}{lll}N= & N=312 & N= \\ 890 & & 578\end{array}$

1.A person infected with HIV can immediately know whether he has been infected by a blood test.

2.After HIV infection, CD4 + T cells will decline first.

49.2

$78.9 \quad 79.5$

78.5

0.05

3.HIV needs CD4 cells as receptors to enter cells.

$56.6 \quad 75.6$

38.4

$38.51^{\star \star *}$

4.People infected with HIV can show no symptoms for months or years.

$\begin{array}{llll}83.8 & 85.3 & 83.0 & 0.37\end{array}$

5.After HIV infection, CD $4+T$ cells first appear cell dysfunction, which is mainly manifested as defects in the $62.6 \quad 71.8$

57.1

$9.32^{* *}$ recognition and response of soluble antigens.

6.People infected with HIV are not infectious without symptoms.

$91.5 \quad 86.5 \quad 91.5$

$7.45^{\star \star}$

7.Now, AIDS has been regarded as a preventable and controllable chronic disease.

$\begin{array}{llll}42.5 & 39.7 & 43.9 & 0.73\end{array}$

8.Women with HIV can transmit HIV to their babies through breastfeeding.

$\begin{array}{llll}74.6 & 67.9 & 78.2 & 5.62^{*}\end{array}$

9.There is already a vaccine to prevent HIV infection 66.1

71.6 $11.36^{\star \star}$

10.AIDS cannot be cured yet.

$\begin{array}{llll}80.9 & 76.3 & 83.4 & 3.31\end{array}$

11.The number of people living with HIV is the same as people living with AIDS.

$\begin{array}{llll}63.4 & 59.0 & 65.7 & 2.00\end{array}$

12.Abuse of addictive substances increases the chance of contracting HIV.

13.The volume of HIV is smaller than the gap between the molecules of the condom material, so the correct use of condoms cannot reduce the risk of HIV infection.

14.Discrimination against AIDS patients will hinder the progress of AIDS prevention.

$\begin{array}{llll}42.0 & 46.2 & 39.8 & 1.68\end{array}$

$59.6 \quad 40.4$

69.9

$36.63^{* \star *}$

15.Women with HIV can give birth to healthy babies through mother-to- child blocking technology(PMTCT).

16. Highly active antiretroviral therapy (HARRT) is the treatment of AIDS through the combined use of three or more antiviral drugs that can effectively control AIDS.

$82.5 \quad 70.5 \quad 88.9$

$23.77^{\star \star \star}$

$44.3 \quad 53.8$

39.1

$8.93^{* \star}$

53.3

48.7

55.7

1.99 


\begin{tabular}{|c|c|c|c|c|}
\hline \multirow[t]{2}{*}{ Item } & Total & Doctors & Nurses & \multirow{2}{*}{$x^{2}$} \\
\hline & $\begin{array}{l}N= \\
890\end{array}$ & $N=312$ & $\begin{array}{l}N= \\
578\end{array}$ & \\
\hline $\begin{array}{l}\text { 17.Drug blocking can occur within } 72 \text { hours after HIV } \\
\text { exposure. }\end{array}$ & 37.1 & 30.8 & 40.5 & $4.01^{*}$ \\
\hline $\begin{array}{l}\text { 18.After taking antiviral drugs for HIV-infected persons, they } \\
\text { will not be infectious once their viral load drops below the } \\
\text { detection level ( } 20 \text { copies } / \mathrm{ml}) \text {. }\end{array}$ & 67.9 & 69.9 & 66.8 & 0.44 \\
\hline $\begin{array}{l}\text { 19.If HIV-infected persons are given antiviral treatment on } \\
\text { time and in quantity, they can achieve functional treatment } \\
\text { success with almost no impact on lifespan. }\end{array}$ & 29.7 & 37.8 & 25.3 & $7.66^{* \star}$ \\
\hline 20.Saliva is one of the vectors of HIV transmission. & 62.2 & 58.3 & 64.4 & 1.57 \\
\hline $\begin{array}{l}\text { 21.You can tell whether a person is infected with HIV by their } \\
\text { appearance. }\end{array}$ & 82.9 & 72.4 & 88.6 & $18.65^{\star \star \star}$ \\
\hline $\begin{array}{l}\text { 22.HARRT is also known as "cocktail therapy", because the } \\
\text { drug configuration method is very similar to the cocktail } \\
\text { configuration, mixing multiple drugs and using special } \\
\text { methods to mix them well. }\end{array}$ & 58.9 & 72.4 & 51.6 & $18.24^{\star \star \star}$ \\
\hline 23.AIDS can have no symptoms or various symptoms. & 82.0 & 79.5 & 83.4 & 1.05 \\
\hline $\begin{array}{l}\text { 24.As long as you come into contact with the blood, semen, } \\
\text { vaginal secretions, and exudates from severely ulcerated } \\
\text { wounds, you will be infected }\end{array}$ & 34.8 & 29.5 & 37.7 & 3.02 \\
\hline${ }^{\star} . P \otimes 0.05 ;{ }^{* \star} . P \otimes 0.01 ;{ }^{* \star \star} . P \rrbracket 0.001$ & & & & \\
\hline
\end{tabular}

\section{Medical staff's attitude to HIV/AIDS}


Table 5

Medical staff's attitude to HIV/AIDS(\%)

Item $x^{2} / t$

Total Doctors Nurses

$\mathrm{N}=$

890

4.7

$(\mathrm{N}=$

312)

$(\mathrm{N}=$
$578)$

3.8

5.2

0.41

2.Society should not accept people with HIV or AIDS.

3.8

1.3

5.2

$4.21^{\star}$

3.I am afraid of AIDS.

42.9

34.6

47.4

$6.76^{* *}$

4.People with HIV/AIDS are disgusting.

16.2

21.2

13.5

$4.38^{*}$

5.AIDS is the punishment for unethical behavior.

8.3

9.6

7.6

0.53

6.Only people infected with AIDS from blood transfusion deserve sympathy.

7. AIDS patients should be isolated.

25.6

23.1

26.9

21.1

1.93

8.People should support and care for AIDS patients.

9.People living with HIV have the right to use public facilities.

10.Employers have the right to dismiss HIV-infected employees.

11.Schools or kindergartens should not refuse to admit AIDS students and children.

12.Mothers who transmit HIV to their children should be punished.

13.If my friend is infected with AIDS, I will cut off contact with him.

14.Working or studying with people living with HIV will not bother me.

15.If college students are infected with AIDS, they should be expelled from school.

16.People living with HIV can still contribute to society.

17.It is the responsibility of the whole society not to discriminate against HIV-infected/AIDS patients.

$\begin{array}{llll}32.4 & 32.1 & 32.5 & 0.01\end{array}$

$\begin{array}{lll}19.3 & 27.6 & 14.9\end{array}$

$8.5 \quad 12.2$

6.6

$4.08^{*}$

28.8

26.3

30.1

0.72

8.1

7.7

8.3

0.05

69.0

57.7

75.1

$14.33^{\star \star \star}$

72.6

61.5

78.5

$14.73^{\star \star \star}$ 
Total Doctors Nurses

$\begin{array}{lll}N= & (\mathrm{N}= & (\mathrm{N}= \\ 890 & 312) & 578)\end{array}$

890

312) 578)

18.The Ministry of Health should disclose information about people living with HIV to protect citizens.

$\begin{array}{lll}27.6 & 35.3 \quad 23.5\end{array}$

$6.97^{\star \star}$

19.If there are activities to visit AIDS patients, I will participate.

48

20.I don't mind being a colleague with people living with $\quad 41.1$
HIV.

21. Medical staff infected with HIV should be allowed to continue working.

$\begin{array}{llll}29.7 & 30.1 & 29.4 & 0.03\end{array}$

22.People living with HIV/AIDS should not be allowed to work as teachers.

23. Under no circumstances should people living with HIV/AIDS suffer discrimination in employment.

$23.1 \quad 28.8 \quad 20.1 \quad 4.39^{*}$

24. People with HIV/AIDS should be allowed to adopt children.

\begin{tabular}{llll}
\hline 43.8 & 35.3 & 48.4 & $7.16^{\star \star}$ \\
\hline 25.8 & 21.2 & 28.4 & 2.76 \\
& & & \\
\hline 62.18 & $64.34 \pm$ & 60.98 & $3.52^{\star \star \star}$ \\
\pm 9.75 & 8.29 & \pm & \\
& & 10.28 & \\
\hline
\end{tabular}

Total

62.18
\pm 9.75

10.28

${ }^{*} . \mathrm{P} \otimes 0.05 ;{ }^{* *} . \mathrm{P} \otimes 0.01 ;{ }^{* \star *} . \mathrm{P} \otimes 0.001$

The $\chi 2$ test results displayed that there was a statistically significant difference in the answers between the doctors and nurses on 11 items $(2,3,4,7,12,13,16,17,18,22,23)$. After reversing the scores of 12 reverse scoring items $(8,9,11,13,14,16,17,19,20,21,23,24)$ in the HIV/AIDS attitude questionnaire, adds the scores of other items to obtain the total score of each sample. The total score is between 24 and 120 points. The higher the score, the more negative the attitude towards HIV/AIDS. The scores of 890 respondents ranged from 30 to 87, with an average of $62.18 \pm 9.75$. As shown in Table 5, the t-test results show that there were statistically significant differences in 15 items $(1,3,4,5,7,12,13,15,16,17,18,23,24)$ and total scores between the doctors and nurses groups. After controlling for age, marital status, educational, professional title, employment years and other factors, the difference between the two groups was still statistically significant $(\mathrm{OR}=1.55,95 \% \mathrm{Cl}$ : $1.01,2.38)$, and the doctor group's attitude towards HIV/AIDS was more negative. After controlling for these factors, HIV/AIDS knowledge is the influencing factor of the medical staff's attitude towards PLWHA (OR=1.57, 95\% Cl: 1.06), 2.31).

\section{Medical staff's willingness to diagnosis and treat HIV-infected /AIDS patients}


Table 6

Medical staff's willingness to diagnosis and treat HIV-infected /AIDS patient(\%)

Item
Agree \& totally agree

Total Doctors Nurses

$\begin{array}{ll}\mathrm{N}= & \mathrm{N}=312 \quad \mathrm{~N}= \\ 890 & \end{array}$

$\begin{array}{llll}84.5 & 84.6 & 84.4 & 0.00\end{array}$

1.I think it is necessary to do a HIV antibody test for all patients before surgery.

2.All patients in the clinic are potentially infectious and the same preventive measures should be taken.

3.I may be infected with AIDS due to surgical treatment and post-operative care for PLWHA.

4.Medical staff should not refuse to provide services to PLWHA.

5.I think that in clinical practice, PLWHA must be isolated from people infected with other diseases.

6.I think that for PLWHA, such as tumors, surgery and other treatments should be given in time like other non-infected patients.

7.I think that PLWHA should actively inform the doctor or nurse that he is PLWHA when he goes to the hospital.

8.I have the right to refuse service PLWHA.

$25.4 \quad 31.4$

22.1

$4.59^{*}$

9.PLWHA should go to a special hospital for treatment.

$59.6 \quad 60.3$

$59.2 \quad 0.05$

10.I am willing to provide PLWHA with surgical treatment or post-operative care services.

11. If there is an appropriate financial incentive, I am willing to provide PLWHA with surgical treatment or post-operative care.

Total

$38.7 \quad 38.5$

38.8

0.00

$47.9 \quad 49.4$

47.1

0.22

1.44

${ }^{\star} . \mathrm{P} \bigotimes 0.05 ;{ }^{* \star} . \mathrm{P} \llbracket 0.01 ;{ }^{* \star} . \mathrm{P} \llbracket 0.001$

In this study, 11 items in Table 6 were used to evaluate the willingness of all samples for the surgical treatment of PLWHA. Reverse entries 1, 3, 7, 8, 9 are scored as 1 point for answers "disagree" and "totally disagree", 0 points for responses "agree" and "totally agree"; and forward entries 2, 4, 5, 6, 10, 11 are scored as 1 point for answers "agree" and "totally agree", 0 points for responses "disagree" and "totally 
disagree". The scores of 11 items are added together. The higher the score, the stronger the willingness to treat PLWHA.The scores of 890 respondents ranged from 1 to 9 , with an average of $5.52 \pm 1.44$. The t-test results showed that there was no statistically significant difference between doctors' and nurses' willingness to diagnose and treat PLWHA. After controlling for age, gender, education, occupation, title, employment years, and whether or not you have been exposed to PLWHA in the past work, the HIV/AIDS knowledge $(\mathrm{OR}=2.41,95 \% \mathrm{Cl}: 1.31 \sim 4.43)$, and the attitude to PLWHA $(\mathrm{OR}=6.74,95 \% \mathrm{Cl}: 3.59 \sim 12.66)$ are the factors affecting the willingness of medical staff to diagnose and treat PLWHA. The medical staff have a higher accuracy rate of answering the HIV/AIDS knowledge questions but their attitude towards PLWHA is still relatively negative. Their willingness to diagnose and treat PLWHA is weak.

\section{Discussions}

The results of this study showed that it is common for PLWHA to be rejected by the hospital medical staff. $30 \%$ of PLWHA indicated that they have been rejected since they were diagnosed with HIV+. In the past 12 months, nearly $20 \%$ of PLWHA have been rejected. Among them, the rejection rate of clinical surgery is higher. Facing the outbreak of COVID-19 in 2020, a large number of medical staff rushed to the medical front-line desperately. However, when facing PLWHA, some of the medical staff show an entirely opposite attitude by refusing treatment. Chinese medical staff have a lot of misinterpretations about clinical knowledge related to HIV/AIDS ${ }^{[23]}$. At present, AIDS has been regarded as a preventable and controllable chronic disease. If HIV-infected persons receive timely and appropriate antiretroviral treatment, functional treatment can be successfully achieved and life expectancy can almost not be affected[24]. Nearly half of the participants do not understand this; even nearly $40 \%$ of medical staff don't know what cocktail therapy is. Only around $40 \%$ of medical staff understand that "after exposure to HIV, drug blocking can be performed within 72 hours" whilst nearly $40 \%$ of medical staff believe that "as long as they come into contact with the blood, semen, vaginal secretions, and exudates from severely ulcerated wounds from an HIV/AIDS infected person, they will be infected". Therefore, we believe that it is still necessary for doctors and nurses to learn and train HIV/ AIDS-related clinical knowledge to improve the medical staff's willingness to treat PLWHA. Then, why do our Chinese medical staff behave so differently when facing patients with different infectious diseases? At this time we can't help but ask questions about the reasons for this. The intentions that cause Chinese medical staff to reject PLWHA are thought-provoking.

At present, the Chinese medical treatment of PLWHA is mainly carried out through the vertical medical management model of the CDC-Infectious Disease Hospitals. However, the surgical systems of infectious disease hospitals in various regions are not perfect and it is difficult to carry out large-scale surgical operations. Most general hospitals in China will conduct routine HIV antibody testing before surgery. Once a patient is found to be HIV-positive, doctors often tactfully refuse surgery, which makes it difficult for the PLWHA to obtain corresponding medical treatment ${ }^{[25]}$ and due to this, the problems of PLWHA seeking medical treatment and surgery are becoming increasingly prominent. Discrimination against PLWHA among medical workers is widespread ${ }^{[26][27]}$ and their willingness to provide medical services to 
PLWHA is low. This discriminatory attitude directly affects the tendency of HIV-infected people to seek medical treatment and causes high-risk groups of HIV to conceal their infection status and be unwilling to undergo HIV voluntary counseling and testing. It also makes them unwilling to learn knowledge and information to protect themselves and others ${ }^{[28]}$. PLWHA has become an uncontrolled source of infection

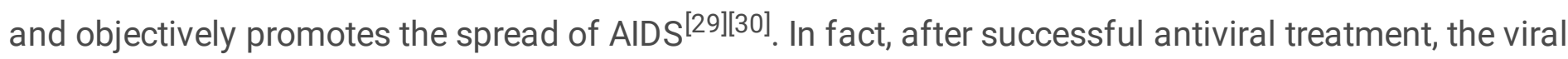
load of HIV-infected people is lower than the detection limit $(20 \mathrm{copies} / \mathrm{ml})$, which is no different from ordinary people and it is not infectious[31]. However, according to the survey results of this study, only nearly $40 \%$ of medical staff clearly expressed their willingness to provide diagnosis and treatment services for PLWHA; which shows the rejection of HIV-infected patients.

Chinese "AIDS Prevention and Control Regulations" clearly states that medical institutions must not shuffle or refuse treatment because the patients they see are PLWHA. The Ministry of Health issued a notice on November 23, 2012, requiring all localities to do a good job in PLWHA antiviral treatment and other medical services, implement the first-diagnosis responsibility system, and strictly prohibit shuffle or refusal of diagnosis and treatment. Whether medical staff are willing to provide medical services for PLWHA is directly related to their lives and health. How can the current Chinese medical staff's refusal behaviors for PLWHA be resolved? We think there are two ways out: the reason for the low willingness of medical staff in diagnosis and treatment and the difficulty of PLWHA surgery is the lack of system, which has nothing to do with medical ethics. System construction should be improved to protect the legal rights and interests of medical staff, solve the problems that may cause damage to their lives and health due to occupational exposure, and mobilize the enthusiasm of the medical staff. The second is "public welfare compensation"; further improving the risk compensation and incentive mechanism for the hospitals and medical staff to receive PLWHA and avoid the worries of doctors so that medical staff will not refuse to treat them.

This study also has certain limitations; for example, we only investigated the PLWHA of a certain CDC WeChat account. Among the 1146 valid samples, men who had sex with men accounted for $86.6 \%$ (992/1146). We believe this is related to the higher education level of men who have sex with men and the daily interaction of friends who rely more on Blued, WeChat, Weibo and other new media. The situation of men who have sex with men is also unique. Our results cannot be generalized to the entire PLWHA group because of sample bias. Due to the difficulty of the actual survey in the PLWHA special population, for the 220 (14.67\%) survey subjects who did not cooperate with the investigation, we did not record their basic information such as age, gender and infection route. Therefore, we cannot give a specific explanation as to whether there is a difference between the situation of the persons who do not cooperate with the investigation and the persons who cooperate, and whether it will affect the results of this research. In addition, we conducted the investigation through the WeChat connection. There are still some differences between WeChat's connection and a face-to-face survey. For example, during the WeChat online survey, it was difficult for us to comprehend the environment of the survey; other details such as the participants' body language were also difficult to observe. Finally, this survey is only a crosssectional survey; the respondents' recall bias or reporting bias on some issues is still out of control. For 
example, some PLWHA cannot recall the previous situation well. In the case of sensitive problems, some respondents may be unwilling to give correct answers and cause reporting bias.

\section{Conclusions}

Rejection by medical staff is a common phenomenon during the treatment of HIV-infected/AIDS patients in China, and the willingness of medical staff to diagnose and treat HIV-infected/AIDS patients is relatively weak, the answer accuracy of HIV/AIDS related knowledge and the attitudes towards HIV/AIDS were the influencing factors for medical staff's willingness to diagnosis and treat HIV-infected /AIDS patients with clinical surgery.

\section{Abbreviations}

PLWHA: People living with HIV and AIDS

CDC: A Center for Disease Control and Prevention

HIV: Human Immunodeficiency Virus

AIDS: Acquired Immune Deficiency Syndrome

OR: Odds ratio

Cl: Confidence interval

NCAIDS: National Center for AIDS/STD Control and Prevention

STD: Sexually transmitted disease

HARRT: Highly Active Anti-Retroviral Therapy

AAS: AIDS Attitude Scale

PMTCT: Mother-to- child blocking technology

\section{Declarations}

\section{Ethics approval and consent to participate}

The study protocol was approved by the Guangxi Normal University Board of Ethics (0108-2018), Ethics Committee of Shizhong District CDC of Jinan $82018-007 \rrbracket$, Ethics Committee of Guangxi Nanxishan Hospital $₫ 2019079 \rrbracket$. Administrative approval was obtained from the Health Officer of Shandong CDC.

A standardized form of verbal informed consent was obtained in this study, which included counseling on the risks, benefits and anonymities. Informed consent was obtained from all the samples and was 
documented on a standardized form that was included in samples' paper study record. The institutional review boards and ethics committees that obtained the verbal informed consent reviewed this study.

\section{Consent to publish}

Not applicable.

\section{Availability of date and materials}

The datasets used and analysed during the current study are available from the corresponding author on reasonable request.

\section{Competing interests}

The authors declare no competing financial interests exist.

\section{Funding}

This study was supported by the Hunan Philosophy and Social Science Foundation Project (16YBA326) and the Hunan Education Department Project (19B517). The funders had no role in study design, data collection and analysis, decision to publish, or preparation of the manuscript.

\section{Authors' Contributions}

YY wrote the initial draft. ZJC revised and translated it. XYL and YL provided overall supervision and critical edits. All authors reviewed the manuscript. The authors read and approved the final manuscript.

\section{Acknowledgement}

The authors would like to acknowledge the PLWHA who participated in the study and the staff of the National Center for AIDS/STD Control and Prevention (NCAIDS) of Shandong CDC for making the study possible. The views expressed in this article are the collective views of the co-authors and do not necessarily represent the official position of the Shandong CDC.

\section{References}

1. Chen D, Liu J, Liu DH.Prediction of ADIS epidemic situation development and analysis of preventioncontrol measurements[J].Chinese Chin. J of PHM,2013,29(01):3-7.

2. NCAIDS, NCSTD, China CDC.Update on the AIDS/STD epidemic in China the third quarter of 2018. Chinese Journal of AIDS \& STD, 2018,24(11):1075.

3. Li D M, Lu S, Li PL, et al.Study on the prevalence of HIV infection and related risk behaviors among male new-type drug users in Qingdao, Shandong province. Chinese Journal of Epidemiology,2018,39(06):750-754. 
4. Zheng, JL, Zhang JF, Luo MY, et Drug resistance after one year of anti-viral treatment in HIV carriers and AIDS patients among men who have sex with men in Zhejiang province. Chinese Journal of Nosocomiology,2020,13(2):128-133.

5. Zeng L, Ma XL, Zhang Y, et Study on the distribution of TCM syndrome types and Syndromes of drug addicts and sexually transmitted patients in a high incidence area of AIDS in Xinjiang. Journal of Xinjiang Medical University, 2020 43(03):325-328.

6. Pu XY, Han Y, Ma YL, et al. (2020). Antiviral treatment effect and influencing factors of $311 \mathrm{HIV}$ positive FSWs in Yunnan province. Chinese Journal of AIDS \& STD (8),2020,26(08):819-823.

7. Zeng Z, Li JB.Epidemic status of AIDS in rural areas and its prevention and control strategies. Occupation and Health, 2020,36(14):2004-2007.

8. Li YW, Huo W, Li W, et al. Research of MSM with HIV / AIDS in the countryside. Chinese Journal of Health Laboratory Technology,2020,30(12):1444-1446.

9. Ji, XY. An investigation onhospital infection knowledge, attitude and intention to refuse patients among oral care professionals in Tianjin[D].Tianjin Medical University .2013.

10. Mockiene V, Suominen T, Maritta Välimäki, et al. Nurses' willingness to take care of people living with human immunodeficiency virus/acquired immunodeficiency syndrome (HIV/AIDS)-does a teaching intervention make a difference?[J]. Nurse Education Today, 2011, 31(6):617-622.

11. Huldrych F. Günthard, et al. Antiretroviral Drugs for Treatment and Prevention of HIV Infection in Adults: 2016 Recommendations of the International Antiviral Society-USA Panel[J]. The Journal of the American Medical Association, 2016,316:191-210.

12. Yu, SQ. (2020). Analysis of Quality of Life and Clinical Effects of Antiviral Treatment for HIV Infected/AIDS Patients. International Infections Diseases(Electronic Edition),2020,9(01):76-77.

13. Yang RR, Yan YK, Gong XM, et al. Study on survival status and its influencing factors of AIDS patients taking antiviral therapy in Ganzhou city from 2006 to 2018. Jiangsu Journal of Preventive Medicine,2020,31(02):122-124.

14. Yang RR, Yan YK, Gong XM, et al. Epidemiological characteristics of AIDS patients taking antiviral therapy for the first time in Ganzhou city from 2006 to 2018. Applied Preventive Medicine,2020,26(02):115-116,118.

15. Vannakit $R$, Janyam $S$, Linjongrat $D$, et al. Give the community the tools and they will help finish the job: key populationed health services for ending AIDS in Thailand[J]. Journal of the International AIDS Society, 2020, 23(6).

16. Xu LM, Li SQ, Peng QL, et al. The clinical characteristics and the cause of death analysis of patients with HIV/AIDS deaths in Shenzhen. Chinese Journal of AIDS \& STD ,2015,21(03):189-193.

17. Ehrenstein, B.P., Hanses, F., Salzberger, B., 2006. Influenza pandemic and professional duty: family or patient's first? A qualitative survey of hospital employees. BMC Public Health 6, 311. doi:10.1186/1471-2458-6-311.

18. Cai, G., Moji, K., Honda, S., Wu, X., 2007. Inequality and unwillingness to care for people living with HIV/AIDS: A survey of medical professionals in Southeast China. AIDS Patient Care and STDs 21 (8), 
$593-603$.

19. Oyeyemi, A., Oyeyemi, A., Abegunde, A., 2008. Knowledge, attitude and willingness of Nigerian physiotherapists to provide care for patients living with Acquired Immunodeficiency Syndrome. Physiotherapy Research International 13 (3), 176-188.

20. Yu Y, Wu T, Li Y, et al. Gay Men's Gender Roles and Mental Health in Guangzhou. China Journal of Health Psychology, 2016, 24(011):1618-1622.

21. Froman RD , Owen SV. Further validation of the AIDS Attitude Scale[J]. Research in Nursing \& Health, 1997, 20(2):161.

22. Sohn A, Park SB. HIV/AIDS Knowledge, Stigmatizing Attitudes, and Related Behaviors and Factors that Affect Stigmatizing Attitudes against HIV/AIDS among Korean Adolescents[J]. Osong Public Health \& Research Perspectives, 2012, 3( 1):24-30.

23. Deng SL, Xiao NY, Wei YZ, et al. Investigation and analysis on the status of HIV occupational exposure protection of medical workers in Wuzhou city. Clinical Research and Practice, 2020, 5(16):17-18.

24. Steven GD, Sharon RL, Diane VH. The end of AIDS: HIV infection as a chronic disease[J]. The Lancet. 2013, 382(9903):1525-1533

25. Meng J. The research of difficult problem in the AIDS virus infection operation-Case analysis of "Xiao Feng event" [D]. Tianjin Normal University.2015.

26. Zhang XL, Zang X H, Wei Y, et al. Analysis on the Qualitative Research on the Discriminatory Attitudes of Medical Staff to AIDS. Modern Women, 2013(8):166-167.

27. Lucia González Fernández, Casas E C , Singh S , et al. New opportunities in tuberculosis prevention: implications for people living with HIV[J]. Journal of the International AIDS Society, 2020, 23(1).

28. Huang, LZ. Investigation of Medical Students' Knowledge and Attitudes about AIDS in Higher Vocational Colleges. The Journal of Medical Theory and Practice, 2015(19):2709-2711.

29. Worthington C , Mollison A, Herman T , et al. A Qualitative Study of Community-Based HIV/AIDS Prevention Interventions, Programs, and Projects for Rural and Remote Regions in Canada: Implementation Challenges and Lessons Learned[J]. Journal of Public Health Management and Practice, 2020:1.

30. Camacho G, Kalichman S, Katner H. Anticipated HIV-Related Stigma and HIV Treatment Adherence: The Indirect Effect of Medication Concerns[J]. AIDS and Behavior, 2020, 24(1):185-191.

31. Véronique Obry-Roguet, Duvivier $C$, Lions $C$, et al. Kaposi sarcoma among people living with HIV in the French DAT'AIDS cohort between 2010 and 2015[J]. Journal of the European Academy of Dermatology and Venereology, 2020, 34(5):1065-1073. 